\title{
Control System Development and Test for the Operation of a Micro-Grid System-PART I
}

\author{
Razzaqul Ahshan, Mohammad Tariq Iqbal, George K. I. Mann, John E. Quaicoe \\ Faculty of Engineering and Applied Science, Memorial University of Newfoundland, St. John's, Canada \\ Email: razzaqul.ahshan@cna.nl.ca
}

Received 14 September 2014; revised 16 October 2014; accepted 6 November 2014

Copyright (C) 2014 by authors and Scientific Research Publishing Inc.

This work is licensed under the Creative Commons Attribution International License (CC BY). http://creativecommons.org/licenses/by/4.0/

(c) (i) Open Access

\section{Abstract}

This paper presents design, analysis and simulation performance of an active power controller for stable and reliable operation of a micro-grid system. Power balance between generation and consumer is a critical issue for stable and reliable operation of the micro-grid systems. This issue becomes more critical when a micro-grid system contains stochastic nature distributed generations such as wind and solar because their output power changes non-uniformly. In order to achieve accurate and fast power balance in such a micro-grid system, power in the system has to be regulated continuously. Such an objective can be achieved using droop based alternating current control technique. Because the droop characteristic employed into the developed controller initiates determining the power deviation in the system which is continuously regulated by controlling the current flow into dump power resistors. The designed controller is simulated for the operation of a micro-grid system in stand-alone mode under various operating conditions. The simulated results show the ability of the developed controller for stable and reliable operation of the microgrid that contains renewable sources. The experimental development of the micro-grid system and the testing of the developed active power controller are presented in PART II of this paper.

\section{Keywords}

Power Balance, Frequency Control, Renewable Energy Sources, Micro-Grid

\section{Introduction}

Increasing energy demand, environmental concern, de-regulated market policy and technology advancement are main causes to integrate distributed generation (DG) units into power system network. Such integration process 
leads the conventional power system to the new power system domain called micro-grid system. A micro-grid system generally composes of DG units with diverse generating capacity, availability, primary energy and operational costs. The application of such DG units in a micro-grid domain requires delivering stable, reliable and sustainable power generation, conversion, storage as well as distribution and exchanging during the entire operational time of the micro-grid system. In order to achieve such operational objectives, coordination and control in a micro-grid system are essential with the consideration of a series of factors such as availability of power generation, operational modes, voltage and frequency limitation, micro-grid load demands, renewable power penetration as well as energy cost [1] [2].

Operation and control of an isolated micro-grid system consisting of renewable power generations become critical because of the stochastic variation in primary energy sources such as wind speed, solar isolation etc. Such variation always leads to the change in active power generated by the DG units in the micro-grid system. As a result the active power generation in the micro-grid system varies randomly that results in an active power mismatches between generation and consumption, which is stochastically varying in nature. Moreover, low inertia in the isolated micro-grid system as compared to a conventional power system along with stochastic behavior in active power mismatches can easily lead the micro-grid system instability. Hence, continuous and smooth active power regulation in an isolated micro-grid system has become an important issue to achieve stable and reliable operation of the system that comprises of renewable power generations such as wind turbines, photovoltaic panels etc.

The growing interest of utilizing renewable power generations in micro-grid domain has turned researchers to address a variety of issues such as architecture, modeling, reliability and cost, operation and control strategies related to micro-grid systems. Several researchers have studied the issues related to frequency control in the micro-grid systems. Power management strategies in a micro-grid system proposed by R. H. Lasseter are carried out by controlling the power angle between the voltage at the voltage source converter and the micro-grid voltage for each micro-source [3], where micro-sources are assumed to be converter interfaced in the micro-grid domain. The successful laboratory test of micro-grid system presented in [3] is performed and reported in [4]. The application of non-inverter interfaced DG units and storage systems in such micro-grid systems is also studied [4]. Power sharing technique among multiple DGs in a micro-grid system is also presented and discussed, where DGs are assumed as inverter interfaced with dispatchable energy sources [5]. In [5], one of the limitations of feeder flow control introduced in [3] is addressed to achieve improved power sharing among DGs which are connected to a common feeder in series during transition between grid connected to island system. Such limitation is solved by employing a method of determining the new droop coefficients during the transition period. Droop based parallel inverter control concept is also adopted to achieve frequency regulation in a wind-solar power source based micro-grid system [6]. A DC/AC pulse width modulated inverter interfaced battery storage system that is used to maintain the micro-grid frequency is presented in [7]. The battery-inverter arrangement is controlled to regulate the magnitude and frequency of its voltage output during the isolated operation of the micro-grid system, according to the power-frequency droop curve. Frequency control in the New Energy and Industrial Technology Development Organization micro-grids is also performed by controlling the active power component of an inverter interfaced battery storage system using power versus frequency droop characteristics [8]. In [9] [10], frequency controller for a micro-grid system is presented, where droop methods and frequency restoration technique are employed to regulate active power component of the inverter interfaced DG units. The DG unit in such micro-grid system is assumed as a DC source. A primary frequency controller is proposed in [11] for variable speed wind energy conversion system in micro-grid operation. The control scheme determines the new operating point of the wind generator unit based on the frequency variation in the micro-grid system. The power at the new operating point provides current reference of the rotor side converter. Parallel inverters control concepts using droop methods are proposed for micro-generations control in a micro-grid system to maintain the active power balance between generation and consumption [12].

A central automatic control system based on estimated load curve is presented for a micro-grid system. Such controller maintains the system frequency by controlling the individual generation units based either on or off depending on the state of the micro-grid frequency [13]. Fuel cell and electrolyzer hybrid system is employed with a dynamic fuzzy proportional-integral controller to ensure real power balance between generation and consumption is studied in [14].

According to the technical literature, parallel inverter control technique based on droop methods has been extensively used to regulate frequency in the micro-grid system. However, it has been reported in [15] because of the droop characteristics; the system frequency may drop to a value that all micro-generation units will be oper- 
ating in a newer operating frequency which may differ from the nominal frequency of the micro-grid system. Thus, a power sharing strategy using static droop characteristics and an adaptive transient droop function is investigated in [15]. Moreover, one of the limitations of parallel inverter control concept is identified and an idea to overcome such limitation is presented in [5].

In [16], auction based theory is applied in pricing strategy for solar-powered micro-grid system, where supply and demand issue is considered as a Potluck problem. A dynamic model of a hybrid system along with an optimal control issue for real time operation is discussed and presented in [17]. A STATCOM based control technique for power quality improvement of a grid connected wind turbine system is proposed, and the proposed control technique showed the significant improvement in power quality in an integrated wind generator, STATCOM and battery energy storage system [18].

In this paper, a micro-grid system comprising of wind power generation system and a small hydro generation unit is presented. The system is located at Fermeuse, Newfoundland, Canada. An active power regulation scheme for stable and reliable operation of such a micro-grid system in an isolated condition has been developed and presented. The proposed scheme is designed to accommodate excess active power in the micro-grid system generated by variable speed wind power generation system in a continuous fashion. Stochastically varying active power in the isolated micro-grid system can be accommodated either by storing energy as water head potential or by using heat load (or resistive dump load) or a combination of both. The performance of the designed controller is tested through simulation in stand-alone mode under various operating conditions of the micro-grid system. The results indicate that the developed active power controller is capable to maintain smooth power balance during stand-alone mode of operation. Also, the controller shows the ability to maintain stable and reliable operation of the micro-grid system that contains only renewable sources.

\section{The Micro-Grid System}

A micro-grid system is a pliable combination of loads, DG units, storage systems either centrally or individually, and interfaced power conditioning units. Such combination can be operated as a single controllable system to provide electric power or electric power and heat to loads within the micro-grid service domain. Wind turbines, solar panels, fuel cells, hydro units and/or non-renewable energy sources are the commonly used DG units in the micro-grid system. However, the combination of the DG units in a micro-grid domain depends upon sites and the availability of the primary energy sources in the site. Micro-grid systems provide benefits to the utility operators and investors, DG owners and customers. Such benefits may include reliable power supply to loads, efficient power transmission, reduction in transmission system expansion and increases renewable power penetration [3] [9] [19].

\section{Fermeuse Micro-Grid System}

This research considers a micro-grid system located at Fermeuse, Newfoundland, Canada. The Fermeuse system consists of 9 WTs, a hydro generation unit (HGU), transmission lines, transformers, a storage unit and two loads. Also, the Fermeuse system includes a link for utility-connected mode of operation. It is important to note that the combination of DG units in the micro-grid system is from renewable energy sources. Figure 1 shows the single line diagram of the Fermeuse system. Data for the buses of the study micro-grid are provided in Table 1. Also, the data for transmission lines and transformers are provided in Table 2.

In order to study and observe the entire operational behavior of the micro-grid system, three operational modes are considered and are conceptually shown in Figure 2. Such operational modes are: 1) utility grid connected, 2) isolated micro-grid with wind power generation system, and 3) isolated micro-grid without wind power generation system [20]. During any operating mode, the active and reactive powers balance in a micro-grid system can be stated as:

$$
\begin{gathered}
\Delta P_{E}=P\left(v_{\omega}\right)+P(h)-P_{L 1}-P_{L 2} \\
\Delta Q_{E}=Q\left(v_{\omega}\right)+Q(h)-Q_{L 1}-Q_{L 2}
\end{gathered}
$$

where $v_{\omega}$ is the wind speed, $P(h)$ and $Q(h)$ are active and reactive power outputs of the hydro unit, and $P_{L 1}, Q_{L 1}, P_{L 2}$ and $Q_{L 2}$ are active and reactive power of loads $L 1$ and $L 2$ respectively.

The study concludes that when the micro-grid is operated in utility-connected mode, the excess powers, $\Delta P>0$ and $\Delta Q>0$ are supplied to the grid, while $\Delta P<0$ and $\Delta Q<0$ are delivered from the utility grid. 


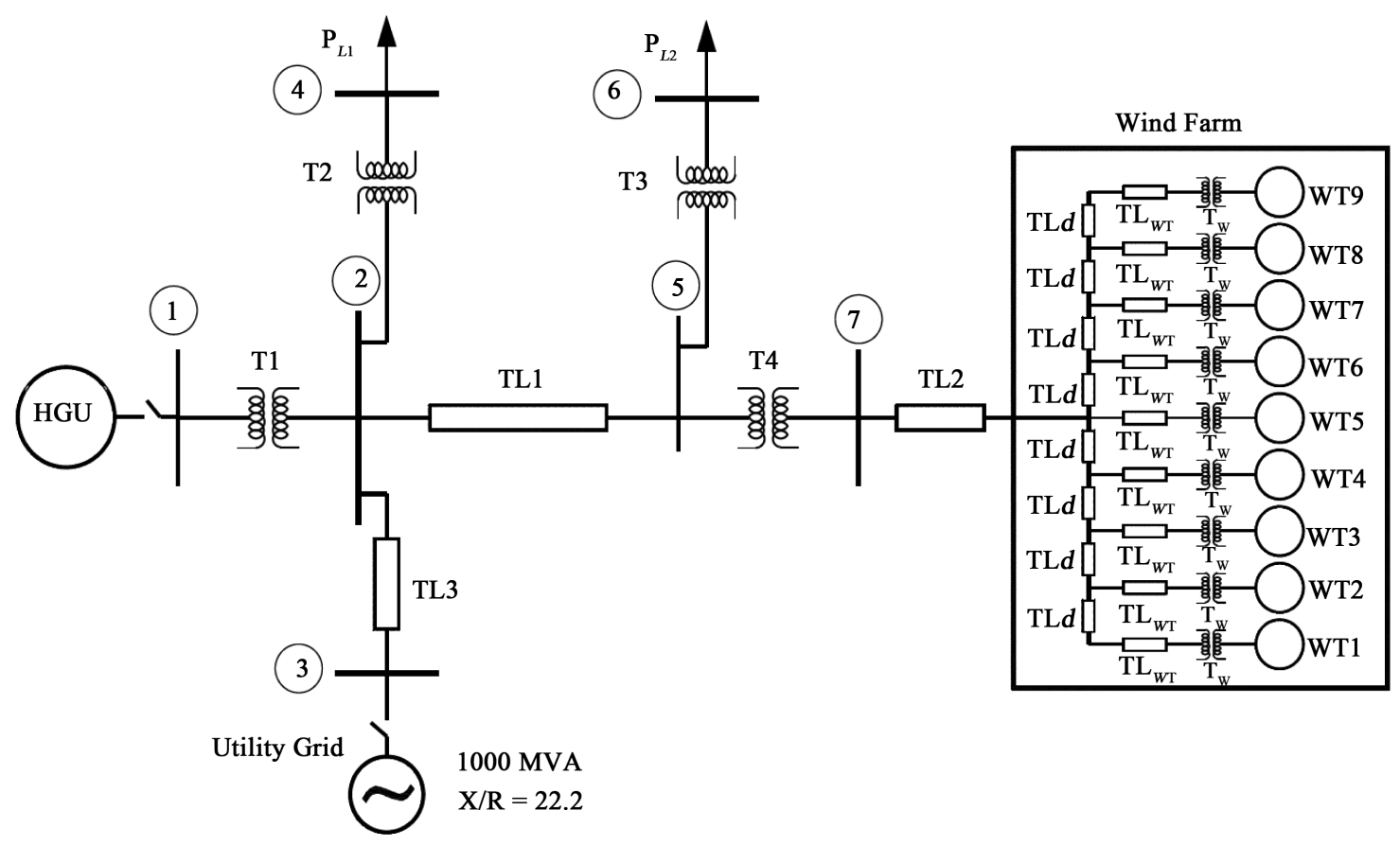

Figure 1. The single-line diagram of the study micro-grid system located in Fermeuse, Newfoundland, Canada.

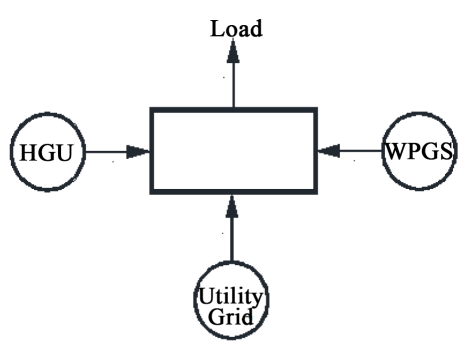

(a)

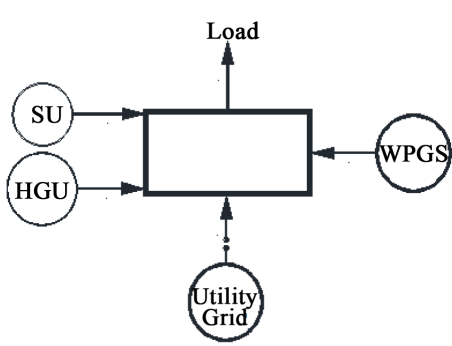

(b)

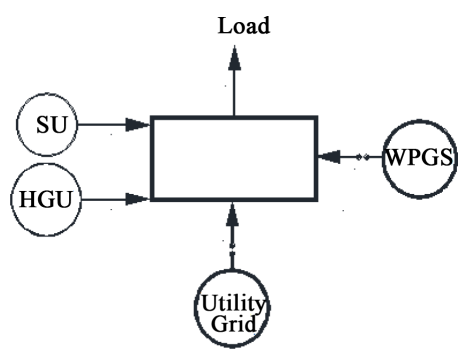

(c)

Figure 2. Conceptual presentation of micro-grid system: (a) Utility-grid connected system; (b) Isolated micro-grid with wind power generation system; (c) Isolated micro-grid without wind power generation system.

Table 1. Fermeuse micro-grid system: Buses.

\begin{tabular}{cccc}
\hline Bus & $P[\mathrm{MW}]$ & $Q[\mathrm{MVAR}]$ & $V[\mathrm{kV}]$ \\
\hline 1 & 7.3 & 6.8 & 6.9 \\
2 & $\Delta P_{E}$ & $\Delta Q_{E}$ & 66 \\
3 & $\Delta P_{E}$ & $\Delta Q_{E}$ & 66 \\
4 & 3.94 & 0.95 & 12.5 \\
5 & 0 & 0 & 66 \\
6 & 2.82 & 0.6 & 12.5 \\
7 & 27 & 12 & 12.5 \\
\hline
\end{tabular}

During isolated micro-grid with wind power generation system operating mode, it also shows that when $\Delta P>0$ and $\Delta Q>0$, the excess powers are required to accommodate continuously either by storing or by supplying to the dump load, and when $\Delta P<0$ due to low wind speed availability, more than one wind turbine is required to switch to supply power demand along with dump load. Also, during isolated micro-grid without wind power generation system operating mode, while $\Delta P<0$ and $\Delta Q<0$, the additional powers are required 
Table 2. Fermeuse micro-grid system: transmission lines and transformers.

\begin{tabular}{cccc}
\hline Components & $V[\mathrm{kV}]$ & $Z[\Omega]$ & $S[\mathrm{MVA}]$ \\
\hline TL1 & 66 & $0.0416+j 0.0663$ & 40 \\
TL2 & 12.5 & $0.0374+j 0.3741$ & 50 \\
TL3 & 66 & $0.002+j 0.0032$ & 40 \\
TLd & 12.5 & $0.00072+j 0.0012$ & 5 \\
TL $W T$ & 12.5 & $0.00006+j 0.000096$ & 10 \\
T1 & $6.9 / 66$ & $0.0854+j 0.8541$ & 5 \\
T2 & $66 / 12.5$ & $0.0493+j 0.493$ & 4 \\
T3 & $66 / 12.5$ & $0.061+j 0.62$ & 40 \\
T4 & $66 / 12.5$ & $0.05+j 0.5$ & 5 \\
TL & $1 / 12.5$ & $0.006+j 0.0625$ & 5 \\
\hline
\end{tabular}

to supply by the SU [20]. It is to be noted that the proposed active power controller in this paper is investigated for an isolated micro-grid with wind power generation system operating mode (Figure 2(b)).

\section{Active Power Controller}

The main objective of the proposed active power control scheme is to maintain continuous and smooth active power balance between generation and micro-grid load. It is worth mentioning that during isolated micro-grid with wind power generation system operating mode, the active power generation in the system varies due to the stochastic variation in wind speeds. Moreover, the power balance in such a micro-grid system has to be achieved by allowing wind generator to operate in optimal power extraction criteria rather forcing wind generator to produce power within a limited capacity of generation. Forcing wind turbine to generate power less than their available power will reduce the turbine efficiency as well as will require additional time to get pay back, which may not be attractive option for investors. Therefore, power control scheme is required to design in a micro-grid system that contains renewable energy sources such as wind turbines by allowing them to operate in their maximum power extraction criteria so that wind generators can produce power at their optimal efficiency. Figure 3 shows the active power control strategy for the operating mode of anisolated micro-grid system with wind power generation system.

During isolated micro-grid with wind power generation system operating mode, the control principle lies into two folds. One is to store energy as water head potential and the other is to shape excess energy using dump load such as heating load. Due to the availability and opportunity to use existing reservoir in the selected site (Fermeuse, Newfoundland, Canada), pumped hydro storage system is proposed for the micro-grid operation. A motor equivalent load is used in the system to present motor-pump set during this operational mode. However, as the wind power varies stochastically and motor-pump set consumes a finite amount of power, the isolated micro-grid system will still have excess active power which is required to shape to maintain the system frequency in an acceptable range $(59.5-60.3 \mathrm{~Hz})$.

The functional block diagram of the developed controller is shown in Figure 4. The controller comprises of phase locked loop, droop calculator, proportional-integral regulator, firing angle calculator, firing pulse generator, switching devices, and resistive dump load. Two thyristor switches are connected in anti-parallel and used in one phase to achieve bi-directional operation. The thyristor switches are selected because of their capability to operate in high power applications [21].

The 3-phase system voltages $V_{s, a b c}$ are utilized in phase locked loop to measure the micro-grid frequency. The measured frequency is compared with the micro-grid base frequency and then input to the frequency-active power droop characterizer. The power variation in the micro-grid system due to the change in the system frequency can be expressed as

$$
\Delta P=-\frac{1}{D_{c}}\left(f_{\text {base }}-f_{\text {mes }}\right)
$$




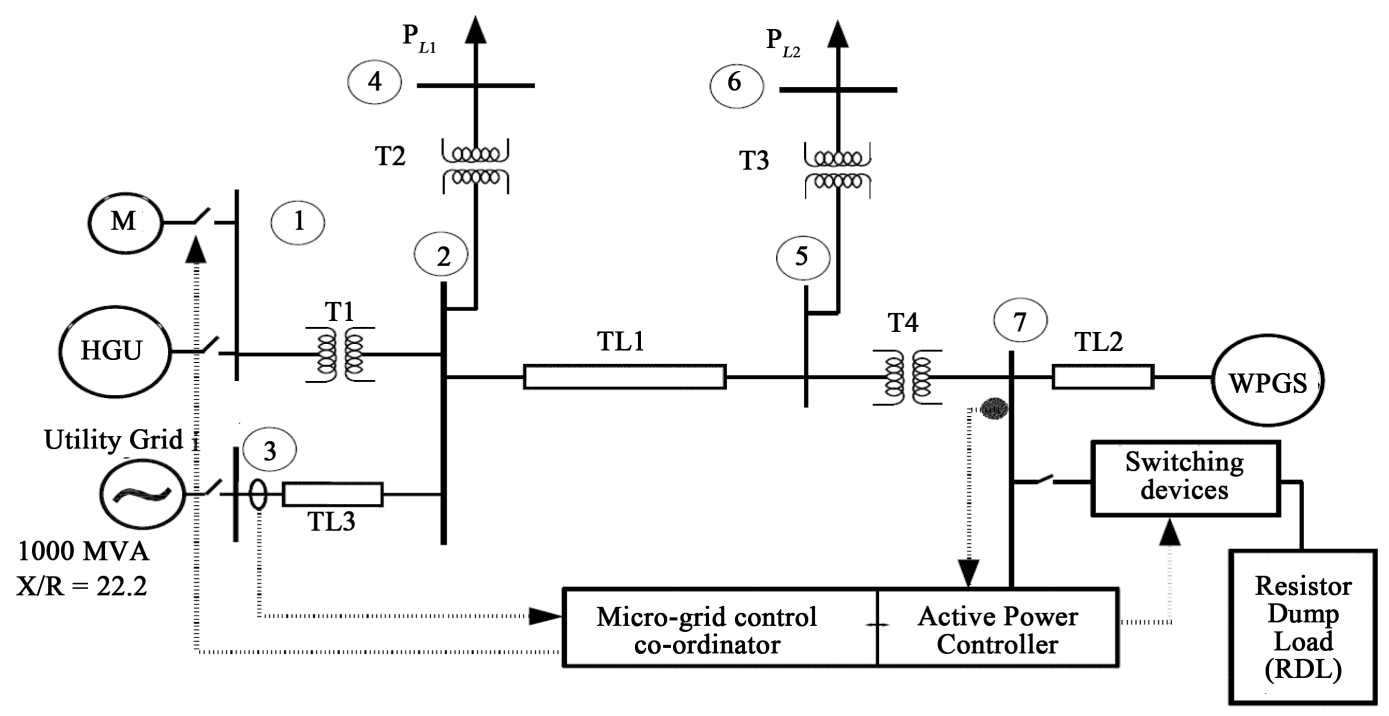

Figure 3. Conceptual diagram of the active power controller along with the micro-grid system.

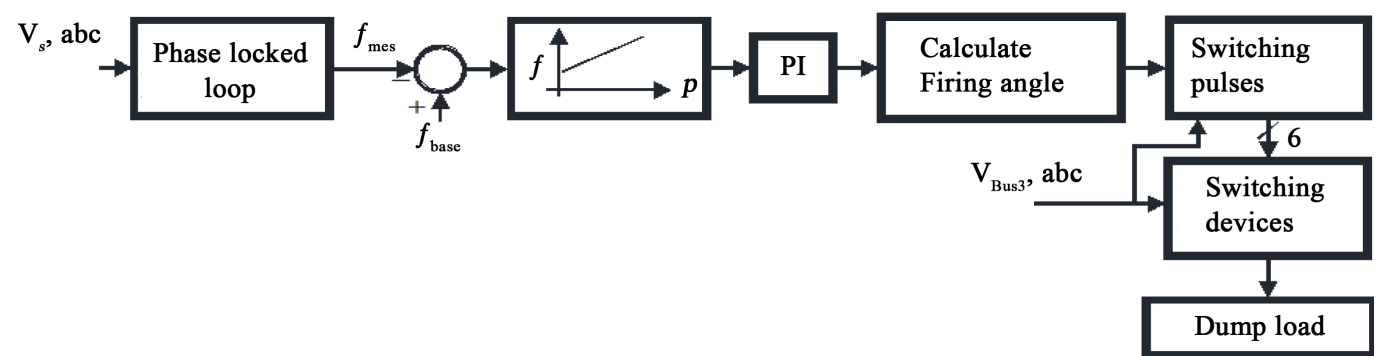

Figure 4. Functional block diagram of the active power controller.

where, $\Delta P$ is the power variation in the micro-grid, $D_{c}$ is the droop coefficient, $f_{\text {base }}$ is the nominal micro-grid frequency and $f_{\text {mes }}$ is the measured frequency from the system. The power $\Delta P$ is passed through the PI regulator to generate the control signal $u_{c s}$ according to (4).

$$
u_{c s}=\Delta P\left(k_{p}+\frac{k_{i}}{s}\right)
$$

where, $k_{p}$ and $k_{i}$ are the proportional and integral gain of the PI regulator. The signal $u_{c s}$ obtained from the PI regulator is employed to calculate the firing angle for the switching devices. The change in control signal create variation in firing angles of switches, which results a change in conduction angle of the switches. The change in conduction angle of the SCR switches causes a change in RMS value of the current flowing into the dump load and results in a change in the amount of real power to be dumped into the dump load. The firing angle generator is represented by a linear equation using the intuition that the higher value of control signal requires lower value of firing angle and vice versa, because lower value of firing angle means allowing more power into the dump load and vice versa. Conceptually, higher value control signals represent larger error or larger power deviation in the micro-grid system which requires absorbing more power from the micro-grid system and vice versa. The relation between the firing angle and control signal based on the principle of SCR switched three phase full wave AC voltage controller is expressed as follows.

$$
\alpha= \begin{cases}-69^{\circ} \times u_{c s}+87^{\circ} & \text { for } 1 \geq u_{c s} \geq 0 \\ 69^{\circ} \times u_{c s}+87^{\circ} & \text { for } 0 \geq u_{c s} \geq-1\end{cases}
$$

The firing angle $\alpha$ and the 3-phase reference voltages are utilized to generate synchronized switching pulses for the switching devices. 


\section{Modeling and Simulation}

The designed active power control scheme described in the preceding section is modeled and simulated in the Matlab/Simulink environment in order to observe its performance. The available model of a phase locked loop and a firing pulse generation unit in the Simpower system library are used in this simulation. The models of power variation coefficient, control signal and firing angle estimator are developed using the available components in Simulink. The simulation is performed for a 20 seconds interval. The designed control scheme is simulated for this case, while a step load is applied to or released from the micro-grid system. The amount of load for a step change is equivalent to a load of a motor-pump set. Since it is necessary to run motor-pump sets to pump water into the upper reservoir for generating power using the stored water, a load equivalent to a motor-pump set is used for step change in the simulation. The simulation for a step load change is also a 20 seconds interval. The grid disconnection occurs at $t=5$ seconds due to a fault or regular maintenance.

\section{Simulation Performance}

A simulation study is carried out on a system consisting of the active power controller along with the micro-grid system based on renewable power generation shown in Figure 3, and the performance results are presented in following figures. The performances of the designed controller are observed for various operating conditions. These conditions are utility grid disconnection and subsequent operation, variable power generation by the wind generators, and step increase and decrease in loading conditions. The micro-grid frequency using the designed active power controller and without the controller are shown in Figure 5 and Figure 6, respectively. Until $t=5$ seconds, the system frequency remains at its rated value as the micro-grid system is connected to the utility grid. At $t=5$ seconds, the utility grid is disconnected from the micro-grid system and the designed active power controller is activated for the operating mode of an isolated micro-grid system with wind power generation.

The frequency of the isolated micro-grid system during utility grid disconnection and in subsequent operation while wind power generation system is connected is shown in Figure 5. Due to the control action of the active power controller, the micro-grid frequency settles to its nominal value after a smooth dynamic change during the time of transition from grid-connected to isolated micro-grid operation. On the other hand, the frequency of the isolated micro-grid system with wind power generation and without an active power controller, shown in Figure 6, starts with a large overshoot at the time of grid disconnection. This overshoot occurs as no control action is

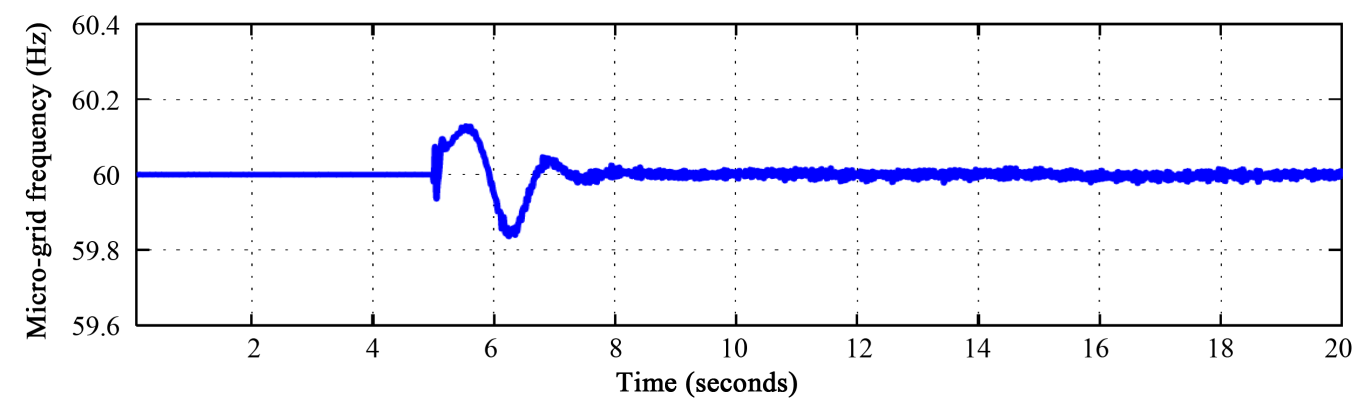

Figure 5. Micro-grid system with active power controller.

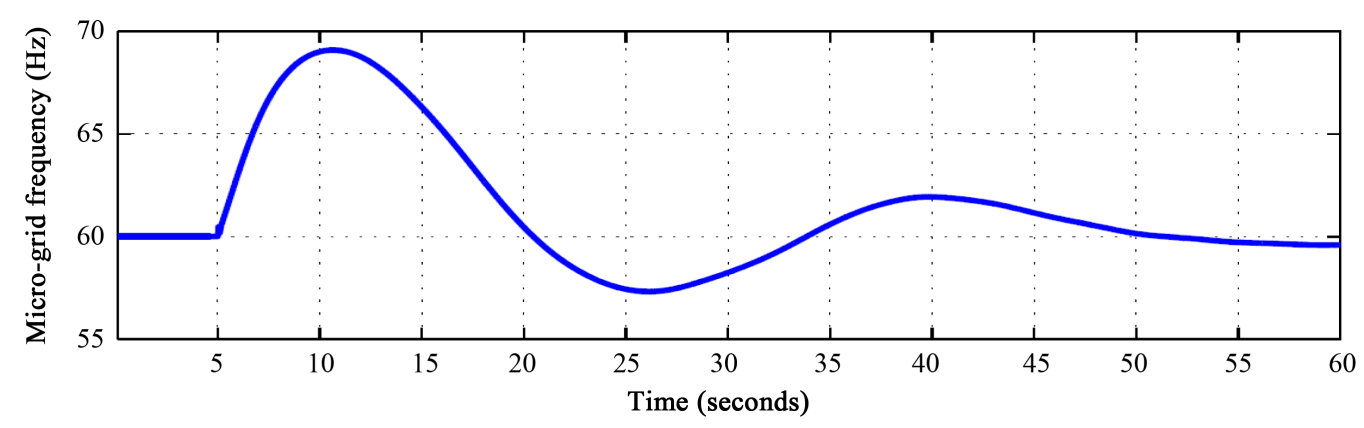

Figure 6. Micro-grid system without active power controller. 
applied to the system. Thus the system frequency response indicates a significant ability of the developed controller to maintain an active power balance between the generation and the loads in the isolated micro-grid system with wind power generation.

The firing angle for the thyristor switches that is derived from control signals at the proportional-integral regulator output, and the average value of the current flowing into the dump load, are shown in Figure 7 and Figure 8, respectively. Figure 7 illustrates that there is a fast, smooth and wide range of change in the firing angles at the beginning of the grid disconnection. These changes allow the controller to be able to accommodate the initial power mismatches during the transition from the utility connection to the isolated mode of operation. The rest of the time, $t=10$ - 20 seconds, the firing angle varies dynamically to adjust the power in the microgrid system that is supplied by the wind power generation system, since the power generation by the wind generator varies according to the change of the wind speed. Furthermore, Figure 8 demonstrates the change in the current flow into the dump load with the variation in firing angles. The variation in the average value of the current flow dictates the variation in power delivered to the dump load, which results an active power balance in an isolated micro-grid system with wind power generation.

The active power controller performances are also verified using step changes in the loading condition, and the simulation results are presented in following Figures. During the utility grid disconnection at $t=5$ seconds, the system frequency varies and then settles down to its rated value smoothly. The frequency of the isolated micro-grid system with wind power generation along with the active power controller is recorded during step changes in load and is shown in Figure 9. The figure illustrates that a dip in system frequency occurs due to the

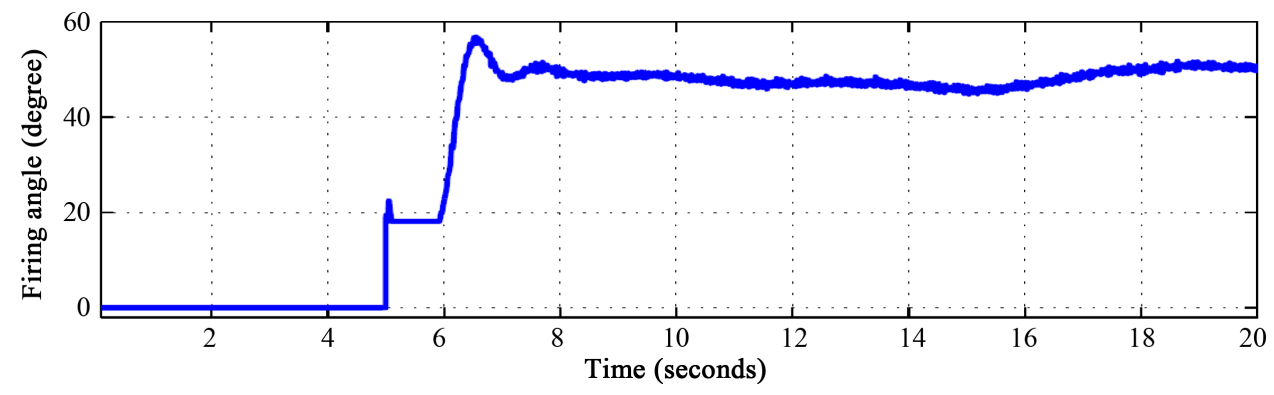

Figure 7. Firing angle for thyristor switches.

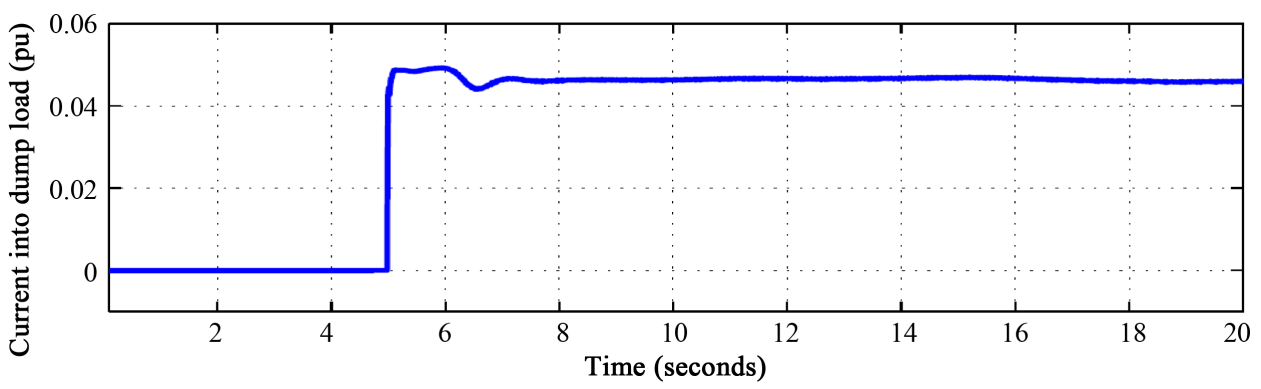

Figure 8. Current flowing into dump load.

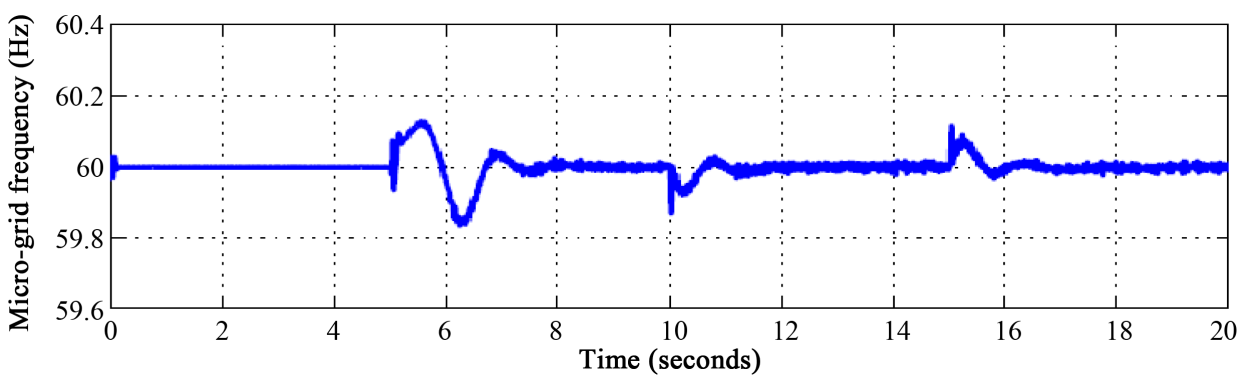

Figure 9. Micro-grid frequency using active power controller with step changes in load. 
change in load demand every time; however, after a short while the frequency settles back to its rated value. Frequency regulation in these operating conditions by adjusting the active power in the system also indicates a significant ability of the designed controller in the isolated micro-grid operation.

An increase step change in load is applied to the system at $t=10$ seconds in an amount of 7.4 percent of the total load demand of the micro-grid system. Similarly, a decrease step change in load is also created in the system at $t=15$ seconds in the same quantity of the load. These step changes in load are applied at the same bus where load-II is connected and are shown in Figure 10. Furthermore, the firing angles for thyristor switches derived from control signals and the current flowing into the dump load during step changes in the load are also shown in Figure 11 and Figure 12, respectively.

Figure 11 illustrates that the firing angle increases at $t=10$ seconds because the micro-grid load demand increases. This condition indicates that there is a requirement to send less power into the dump load. This requirement is achieved by the action of the designed controller and is shown in Figure 12 because less power is supplied to the dump load starting at $t=15$ seconds. Figure 11 also illustrates that the firing angle decreases at $t=$ 15 seconds because micro-grid load demand decreases. This case indicates that there is a need to deliver more power into the dump load. This goal is reached by applying the developed controller action and is shown in Figure 12, because more power is delivered into the dump load starting at $t=15$ seconds.

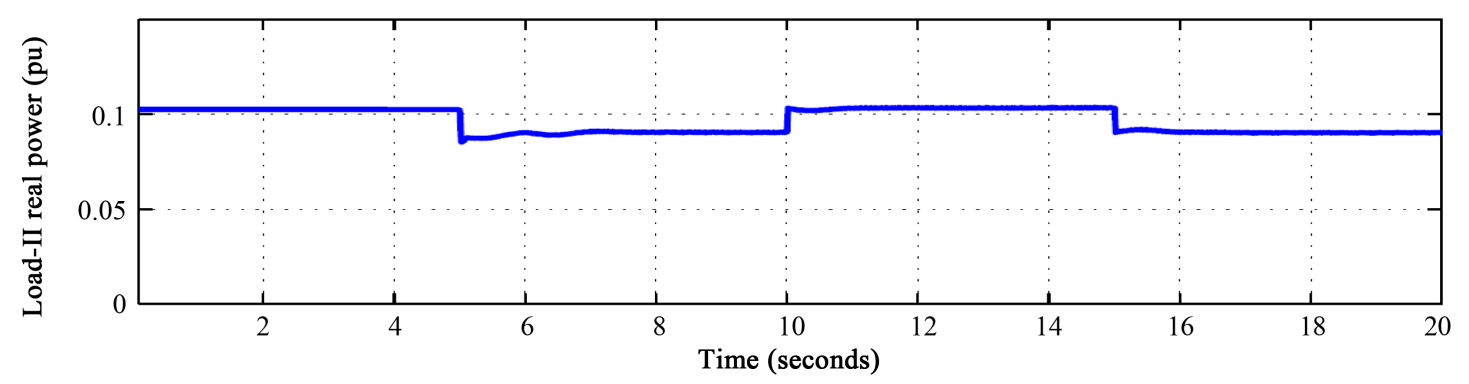

Figure 10. Power consumed by load-II during step change in micro-grid load.

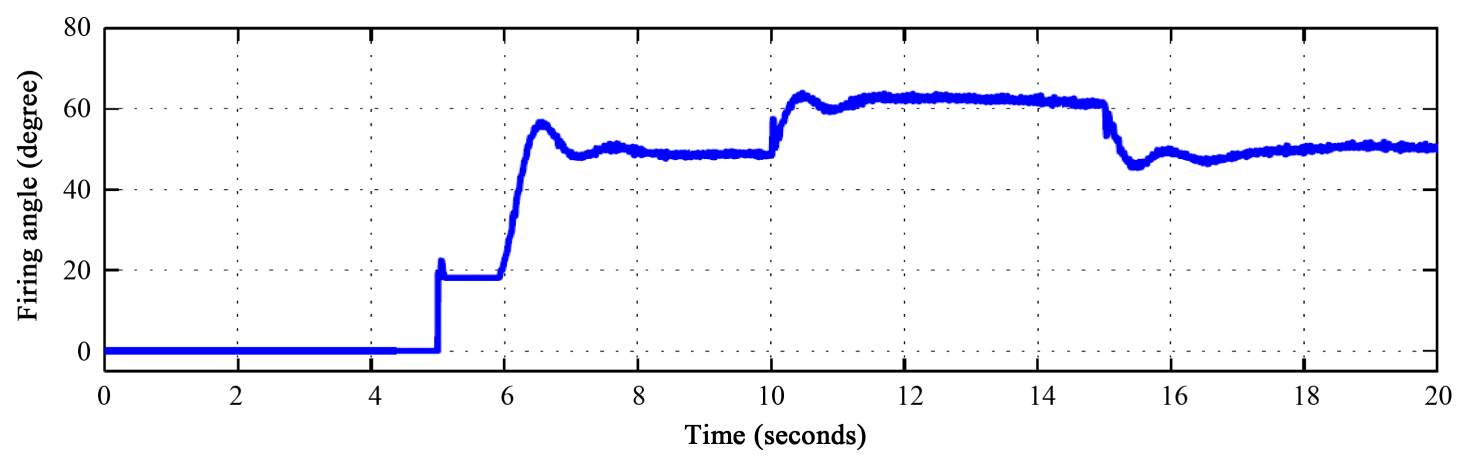

Figure 11. Variation in firing angle for thyristor switches during step changes in load.

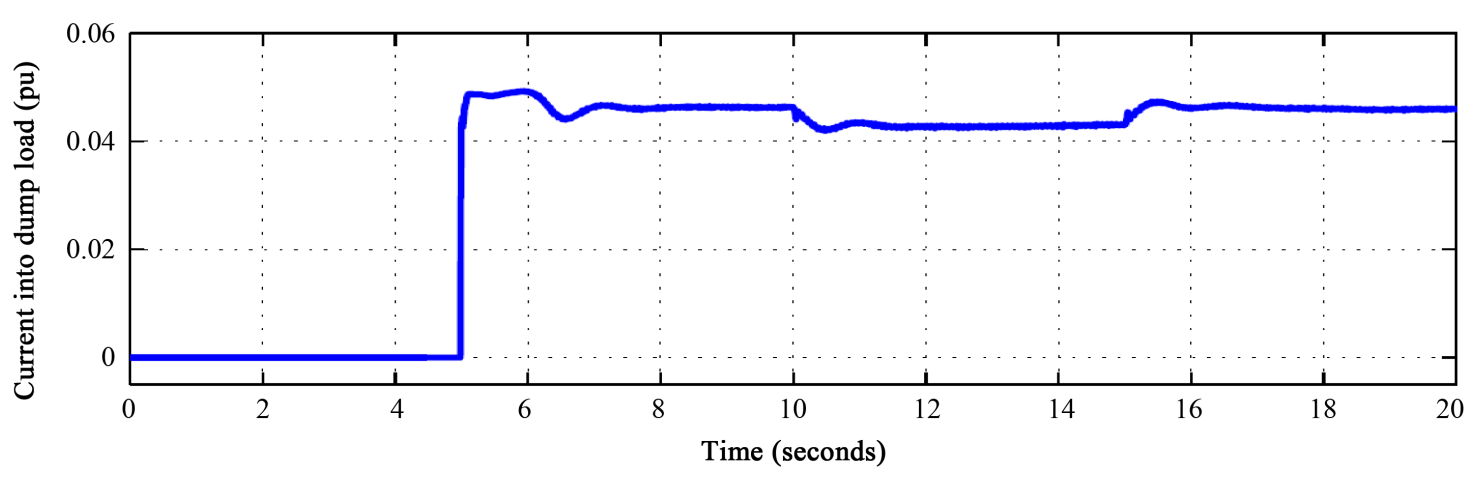

Figure 12. Change in current flow into the dump load during step changes in load. 


\section{Conclusion}

This paper has presented the design, simulation and performance testing of an active power controller for an isolated micro-grid system which contains only renewable energy sources. The controller is developed based on alternating current control technique, where dump load resistor and power-frequency droop characteristics are employed. The controller is modeled and simulated using MATLAB/SIMULINK simulation package. The controller performances are tested through simulation under various operating conditions and satisfactory simulation results are presented in this paper. It is found that the design active controller is capable to maintain the fast and accurate power balance between the generation and load, while a stable and reliable operation was maintained during transition between the grid connected to the isolated micro-grid domain, and in the subsequent operation.

\section{Acknowledgements}

This work is supported by a research grant from the National Science and Engineering Research Council (NSERC) of Canada, the Atlantic Innovation Fund (AIF) Canada, and Memorial University of Newfoundland. The authors would like to acknowledge the utility company, Newfoundland Power, Canada for providing the system information and data.

\section{References}

[1] Mahat, P., Chen, Z. and Bak-Jensen, B. (2010) Under Frequency Load Shedding for an Islanded Distribution System with Distributed Generators. IEEE Transactions on Power Delivery, 25, 911-918. http://dx.doi.org/10.1109/TPWRD.2009.2032327

[2] Katiraei, F. and Iravani, M. (2006) Power Management Strategies for a Micro-Grid with Multiple Distributed Generation Units. IEEE Transactions on Power Delivery, 21, 1821-1831. http://dx.doi.org/10.1109/TPWRS.2006.879260

[3] Lasseter, R.H. (2002) Micro-Grids. IEEE Power Engineering Society Winter Meeting, New York, January 2002, 305308.

[4] Lasseter, R.H., Eto, J.H., Schenkman, B., Stevens, J., Vollkommer, H., Klapp, D., Linton, E., Hurtado, H. and Roy, J. (2011) CERTS Micro-Grid Laboratory Test Bed. IEEE Transactions on Power Delivery, 26, 325-332. http://dx.doi.org/10.1109/TPWRD.2010.2051819

[5] Ahn, S., Park, J., Chung, I., Moon, S., Kang, S. and Nam, S. (2010) Power-Sharing Method of Multiple Distributed Generators Considering Control Modes and Configurations of a Micro-Grid. IEEE Transactions on Power Delivery, 25, 2007-2016. http://dx.doi.org/10.1109/TPWRD.2010.2047736

[6] Ribeiro, L.A.de.S., Saavedra, O.R., Lima, S.L. and Matos, J.G.de. (2011) Isolated Micro-Grids with Renewable Hybrid Generation: The Case of Lenis Island. IEEE Transaction on Sustainable Energy, 2, 1-11.

[7] Georgakis, D., Papathanasiou, S.A., Hatziargyriou, N., Engler, A. and Hardt, Ch. (2004) Operation of a Prototype Micro-Grid System Based on Micro-Sources Equipped with Fast-Acting Power Electronics Interfaces. IEEE 35th Annual Power Electronics Specialists Conference, 4, 2521-2526.

[8] Kojima, Y., Koshio, M., Nakamura, S., Maejima, H., Fujioka, Y. and Goda, T. (2007) A Demonstration Project in Hachinohe: Micro-Grid with Private Distribution Line. IEEE International Conference on System of Systems Engineering, San Antonio, 16-18 April 2007, 1-6.

[9] Katiraei, F. and Iravani, M.R. (2005) Transients of a Micro-Grid System with Multiple Distributed Energy Resources. International Conference on Power Systems Transients, Montreal, 19-23 June 2005, Paper No. IPST05-080.

[10] Katiraei, F., Iravani, M.R. and Lehn, P.W. (2005) Micro-Grid Autonomous Operation during and Subsequent to Islanding Process. IEEE Transaction on Power Delivery, 20, 248-257. http://dx.doi.org/10.1109/TPWRD.2004.835051

[11] Shahabi, M., Haghifam, M.R., Mohamadian, M. and Nabavi-Niaki, S.A. (2009) Microgrid Dynamic Performance Improvement Using a Doubly Fed Induction Wind Generator. IEEE Transactions on Energy Conversion, 24, 137-145. http://dx.doi.org/10.1109/TEC.2008.2006556

[12] Majumder, R., Ghosh, A., Ledwich, G. and Zare, F. (2009) Load Sharing and Power Quality Enhanced Operation of a Distributed Micro-Grid. IET Renewable Power Generation, 3, 109-119. http://dx.doi.org/10.1049/iet-rpg:20080001

[13] Kawasaki, K., Matsumura, M., Iwabu, K., Fujimuram, F. and Iima, T. (2009) Autonomous Dispersed Control System for Independent Micro-Grid. Journal of Electrical Engineering, Japan, 166, 1121-1127.

[14] Li, X., Song, Y. and Han, S. (2008) Frequency Control in Micro-Grid Power System Combined with Electrolyzer System and Fuzzy PI Controller. Journal of Power Sources, 180, 468-475. 
http://dx.doi.org/10.1016/j.jpowsour.2008.01.092

[15] Mohamed, Y.A.I. and El-Saadany, E.F. (2008) Adaptive Decentralized Droop Controller to Preserve Power Sharing Stability of Paralleled Inverters in Distributed Generation Micro-Grids. IEEE Transactions on Power Electronics, 23, 2806-2816. http://dx.doi.org/10.1109/TPEL.2008.2005100

[16] Maity, I. and Rao, S. (2010) Simulation and Pricing Mechanism Analysis of a Solar-Powered Electrical Micro-Grid. IEEE Systems Journal, 4, 275-284. http://dx.doi.org/10.1109/JSYST.2010.2059110

[17] Dagdougui, H., Minciardi, R., Ouammi, A., Robba, M. and Sacile, R. (2010) A Dynamic Decision Model for the Real-Time Control of Hybrid Renewable Energy Production Systems. IEEE Systems Journal, 4, 323-333. http://dx.doi.org/10.1109/JSYST.2010.2059150

[18] Mohod, S.W. and Aware, M.V. (2010) A STATCOM-Control Scheme for Grid Connected Wind Energy System for Power Quality Improvement. IEEE Systems Journal, 4, 346-352.

[19] Barklund, E., Pogaku, N., Prodanovi'c, M., Aramburo, C.H. and Green, T.C. (2008) Energy Management in Autonomous Micro-Grid Using Stability-Constrained Droop Control of Inverters. IEEE Transactions on Power Electronics, 23, 2346-2352. http://dx.doi.org/10.1109/TPEL.2008.2001910

[20] Ahshan, R., Iqbal, M.T., Mann, G.K.I. and Quaicoe, J.E. (2010) Micro-Grid System Based on Renewable Power Generation Units. Proceedings of the 23rd Canadian Conference on Electrical and Computer Engineering, Calgary, 2-5 May 2010, 1-4.

[21] Rashid, M.H. (2005) Power Electronics: Circuits, Devices and Applications. 3rd Edition, Prentice-Hall, New Delhi. 
Scientific Research Publishing (SCIRP) is one of the largest Open Access journal publishers. It is currently publishing more than 200 open access, online, peer-reviewed journals covering a wide range of academic disciplines. SCIRP serves the worldwide academic communities and contributes to the progress and application of science with its publication.

Other selected journals from SCIRP are listed as below. Submit your manuscript to us via either submit@scirp.org or Online Submission Portal.
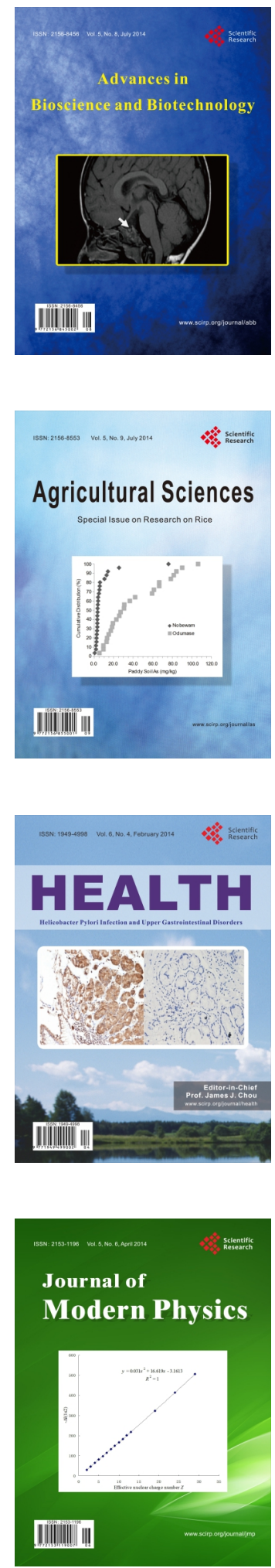
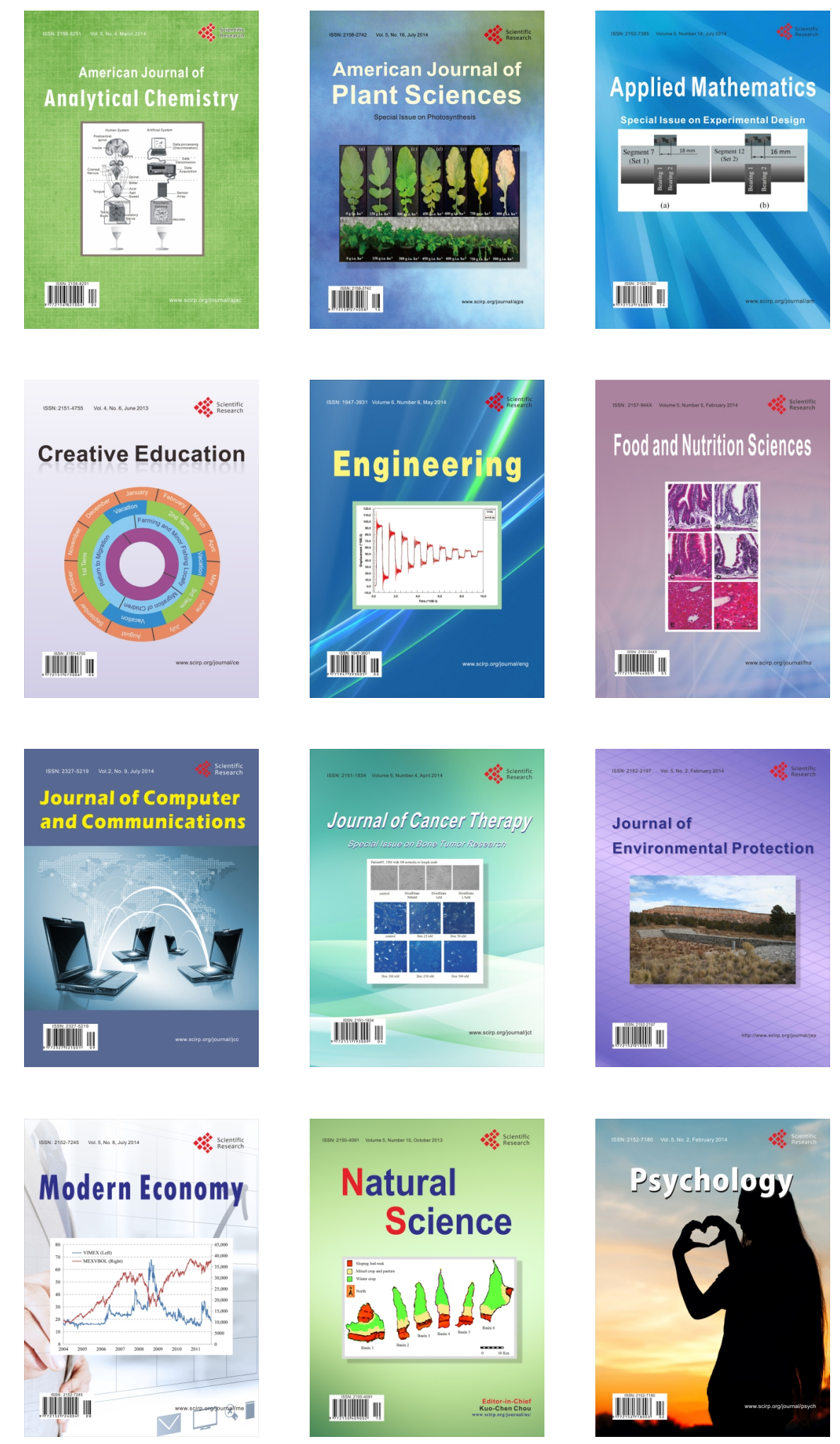